\title{
Long-term recording of some fish diseases using general fishery research surveys in the south-east part of the North Sea
}

\author{
P. van Banning \\ Netherlands Institute for Fishery Investigations, PO Box 68, 1970 AB IJmuiden, The Netherlands
}

\begin{abstract}
Long-term (1981-1985) results of recording several diseases of dab, plaice and cod are presented for the south-east area of the North Sea. The occurrence of each disease is geographically plotted, and observed average and maximum prevalence levels are given and discussed. Results underline that diseases in marine wild fish stocks can differ strongly per fish species, area and season. Fish disease recording in standard stock-assessment surveys can be considered potentially useful and largely agrees with prevalence levels observed during special fish disease surveys in the same area.
\end{abstract}

\section{INTRODUCTION}

Historically, attention has long been paid to the presence of diseases in marine wild fish (e.g. Johnstone 1906), but most of the early studies can be classified as single or short-time observations. Continuous longterm studies from the past are missing, resulting in current absence of reliable data for comparison in establishing whether present disease prevalences in marine wild fish stocks have changed abnormally or exceeded natural prevalence levels.

Research interest in the presence and cause of diseases in wild marine fish has significantly increased in the last decade. This development is mainly the result of questions being raised on the effects of environmental factors (especially pollution-related effects) and on the presence of epidemical changes in wild sea fish populations. In facing these questions a serious lack of useful background or base-line information was appar- ent, especially concerning long-term data estimating natural levels of prevalences.

The prevalence of diseases is the result of a complex interaction in which many environmental factors of physical, chemical and biological origin play a role. This means that the prevalences of diseases in marine wild fish can be expected to fluctuate per fish species, area and time. To obtain base-line data providing better insights into disease prevalence fluctuations in marine wild fish stocks, a fish disease recording programme was carried out for 5 consecutive years.

\section{MATERIALS AND METHODS}

Selection of methods, fish and diseases. Special fish disease surveys are problematic for reasons of finance (high costs of sea-going vessels) and staffing (difficulties in finding sufficient numbers of specialists), espe-

Table 1. Length data $(\mathrm{cm})$ of fish sampled in the disease recording programme 1981-1985

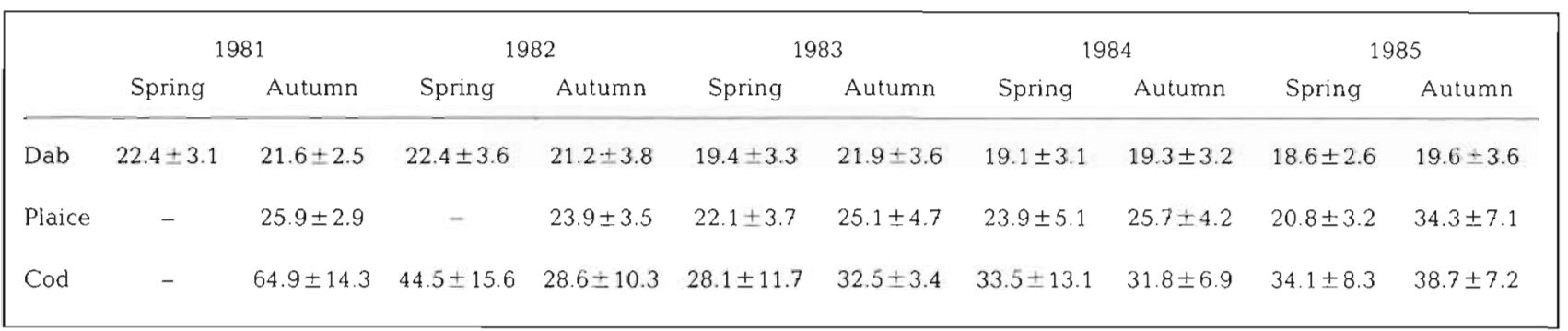



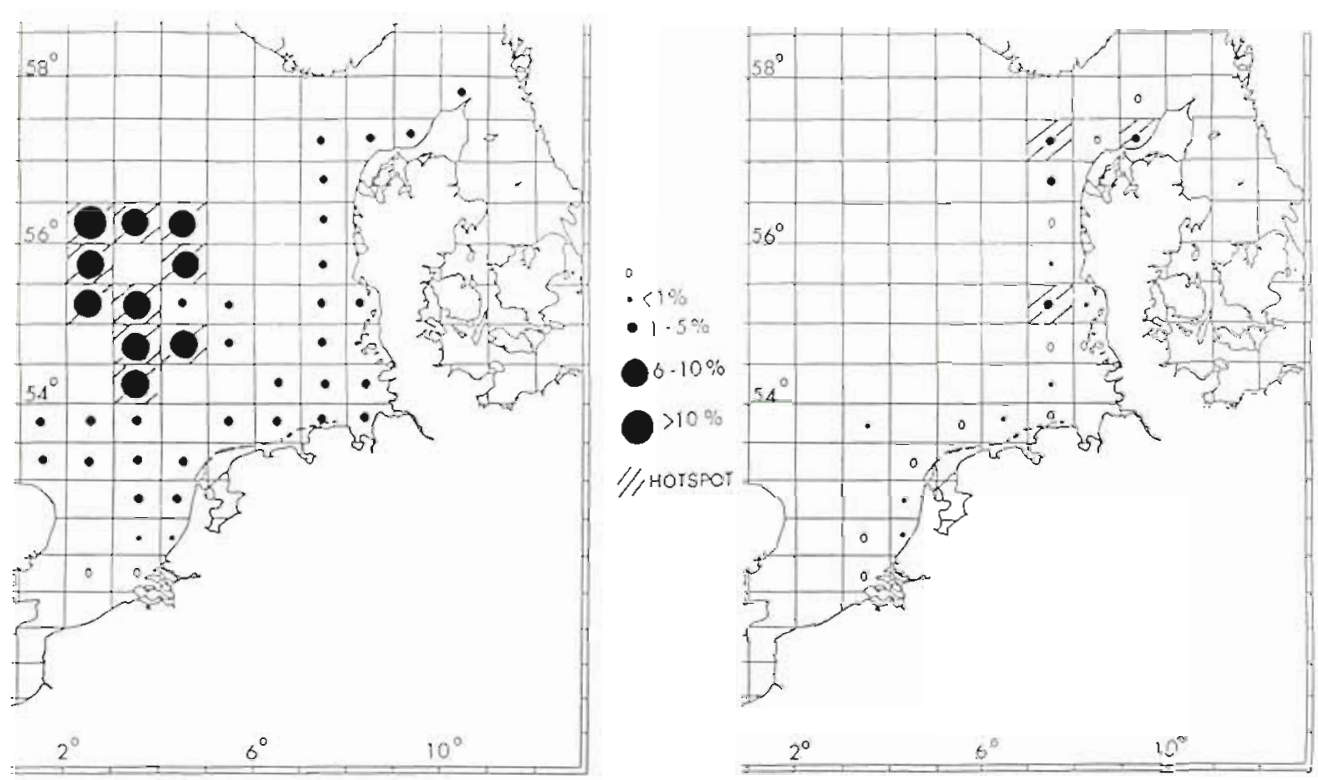

Fig. 1. Presence of lymphocystis in dab, 1981-1985, plotted per area and season. Left: Feb-Apr; right: Sep-Oct cially when long-term surveys are scheduled. Hence the fish disease recording programme was incorporated into some standard sea surveys of the Dutch fishery research, imposing restrictions on the choice of areas and handling of fish. The latter meant also that diseases had to be chosen for investigation which are easily recognisable by the naked eye, and that a selection of fish species had to be made for survey. Consequently, the programme was directed at dab Limanda limanda, plaice Pleuronectes platessa and cod Gadus morhua and involved the diseases lymphocystis (viral skin disease), hyperplasia/papilloma (skin disease associated with a virus [Bloch et al. 1986], young stages indicated as hyperplasia, older stages as papilloma), skin ulcers (skin lesions of bacterial origin), presumptive mycobacteriosis (possible bacterial infection, mainly internal), Glugea stephani (protozoan infection, mainly in intestine) and Myxobolus aeglefini (protozoan infection, mainly of cranium). The fish sampled were selected from specimens with lengths of $15 \mathrm{~cm}$ or more (for average lengths of sampled fish, see Table 1) for a disease check. It was considered that dab, plaice and cod specimens below $15 \mathrm{~cm}$ were immature or very young, living for a short time in the environment fished; hence they would have had too short a time (including incubation) or a too restricted a chance to develop and clearly reveal the diseased conditions under investigation.

No special sex-separated recording and presentation was carried out, because no sex-linked results were expected with the type of infectious diseases and fish species studied, as was for instance indicated by Wolth-
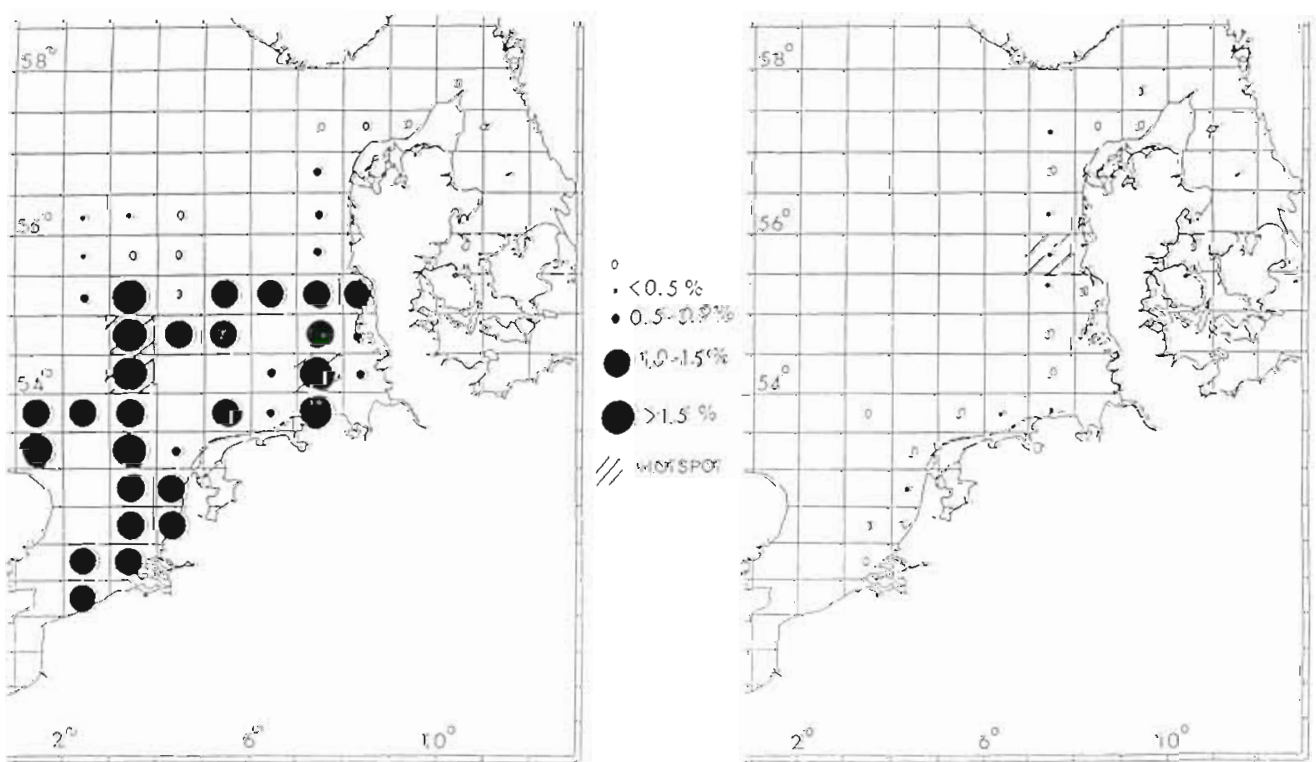

Fig. 2. Presence of hy perplasia/papilloma in dab, 1981-1985, plotted per area and season Left: Feb-Apr; right: Sep-Oct 
Fig. 3. Presence of ulcers in dab, 1981-1985, plotted per area and season. Left: Feb-Apr; right: Sep-Oct
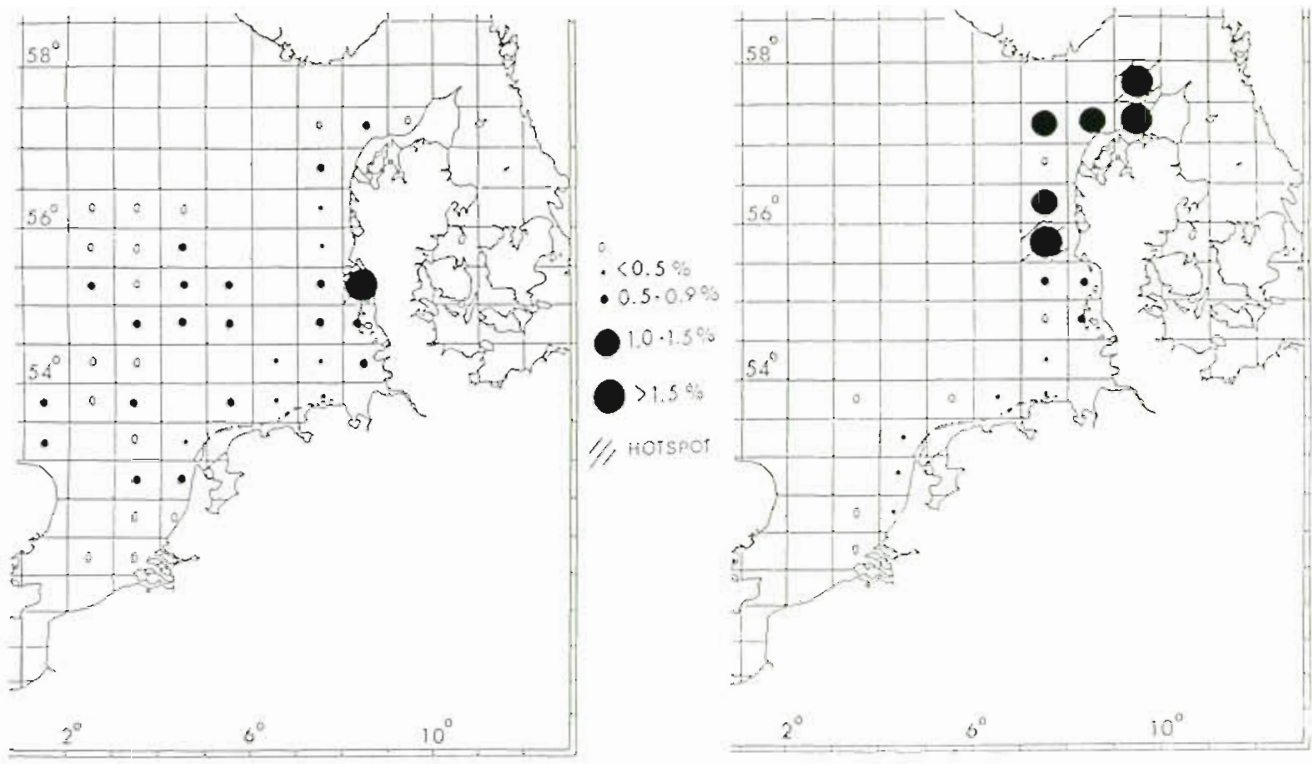

Table 2. Prevalences of lymphocystis in dab, 1981-1985. Below: Prevalence trend (solid line: spring; dotted line: autumn)

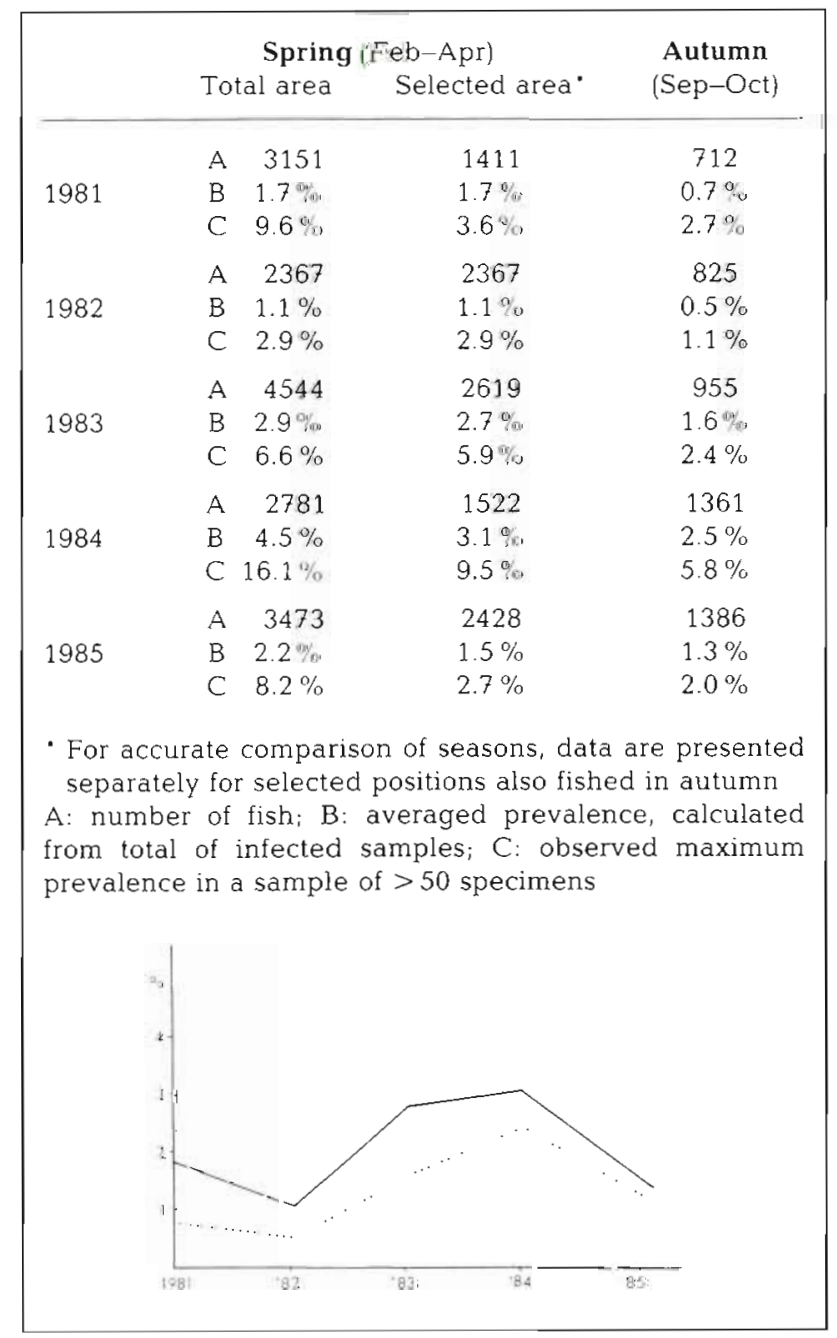

Table 3. Prevalences of hyperplasia/papilloma in dab, 1981-1985. Below: Prevalence trend (solid line: spring; dotted line: autumn)

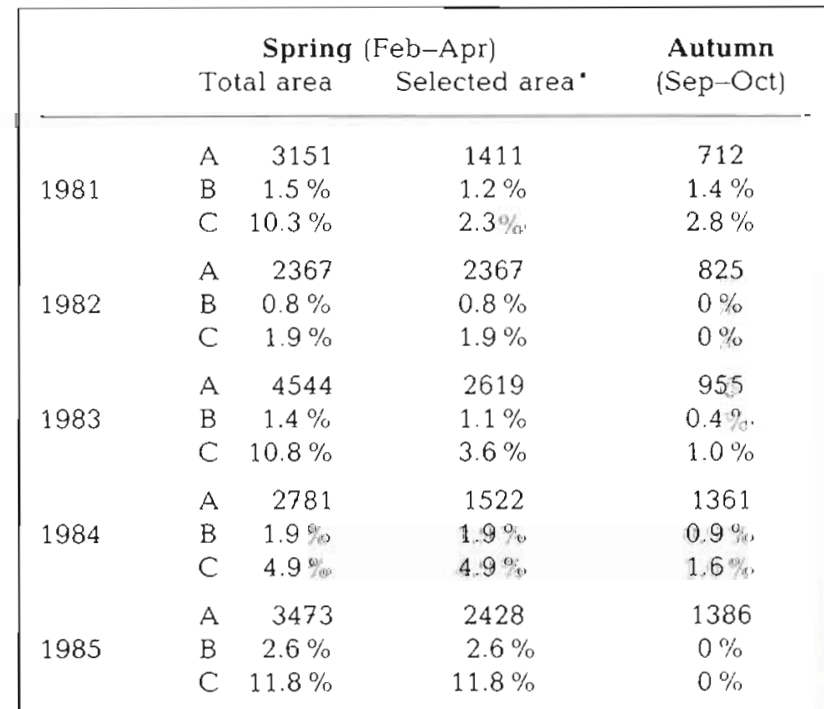

- For accurate comparison of seasons, data are presented separately for selected positions also fished in autumn A: number of fish; B: averaged prevalence, calculated from total of infected samples; $C$ : observed maximum prevalence in a sample of $>50$ specimens

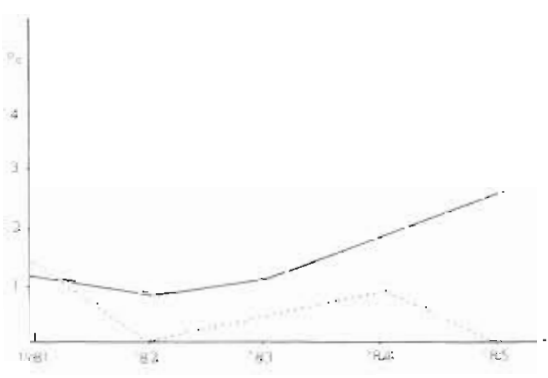



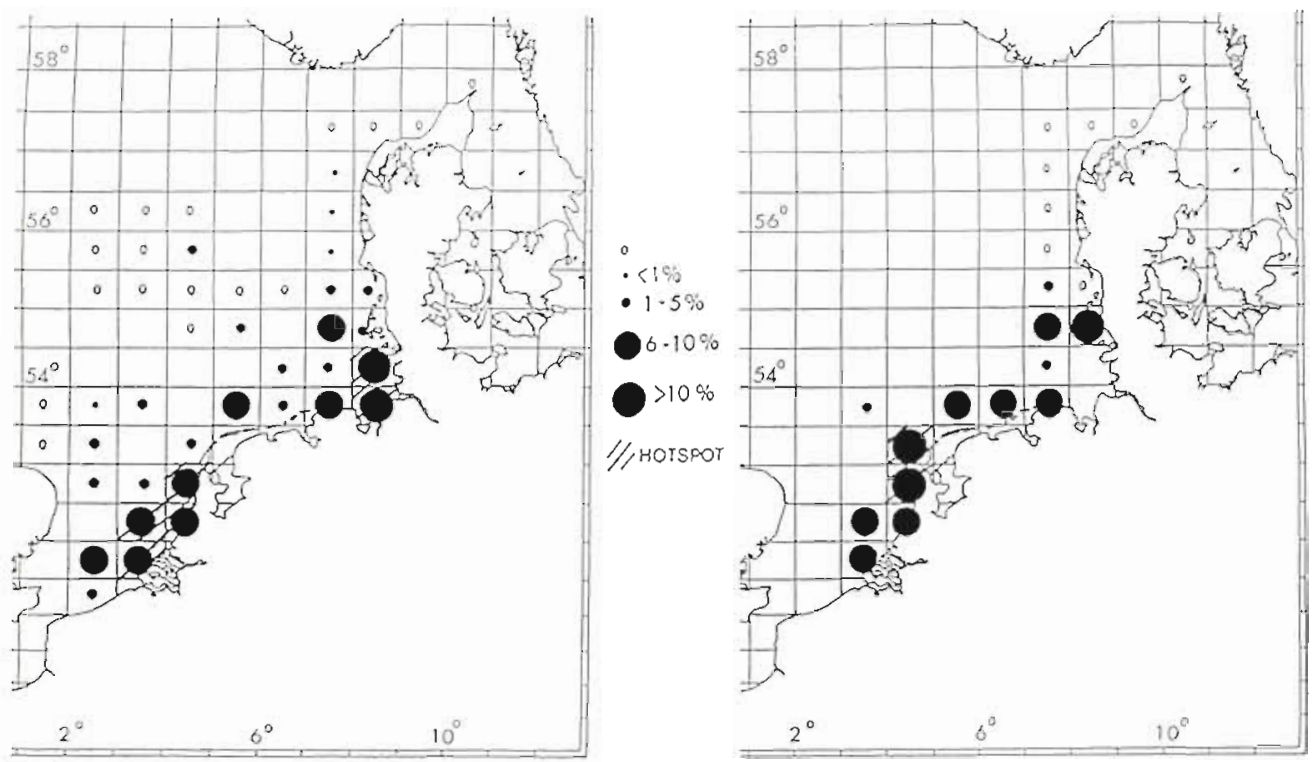

Fig. 4. Presence of Glugea stephani in dab 1981-1985, plotted per area and season. Left: Feb-Apr; right: Sep-Oct

Table 4. Prevalences of ulcers in dab, 1981-1985. Below Prevalence trend (solid line: spring; dotted line: autumn)

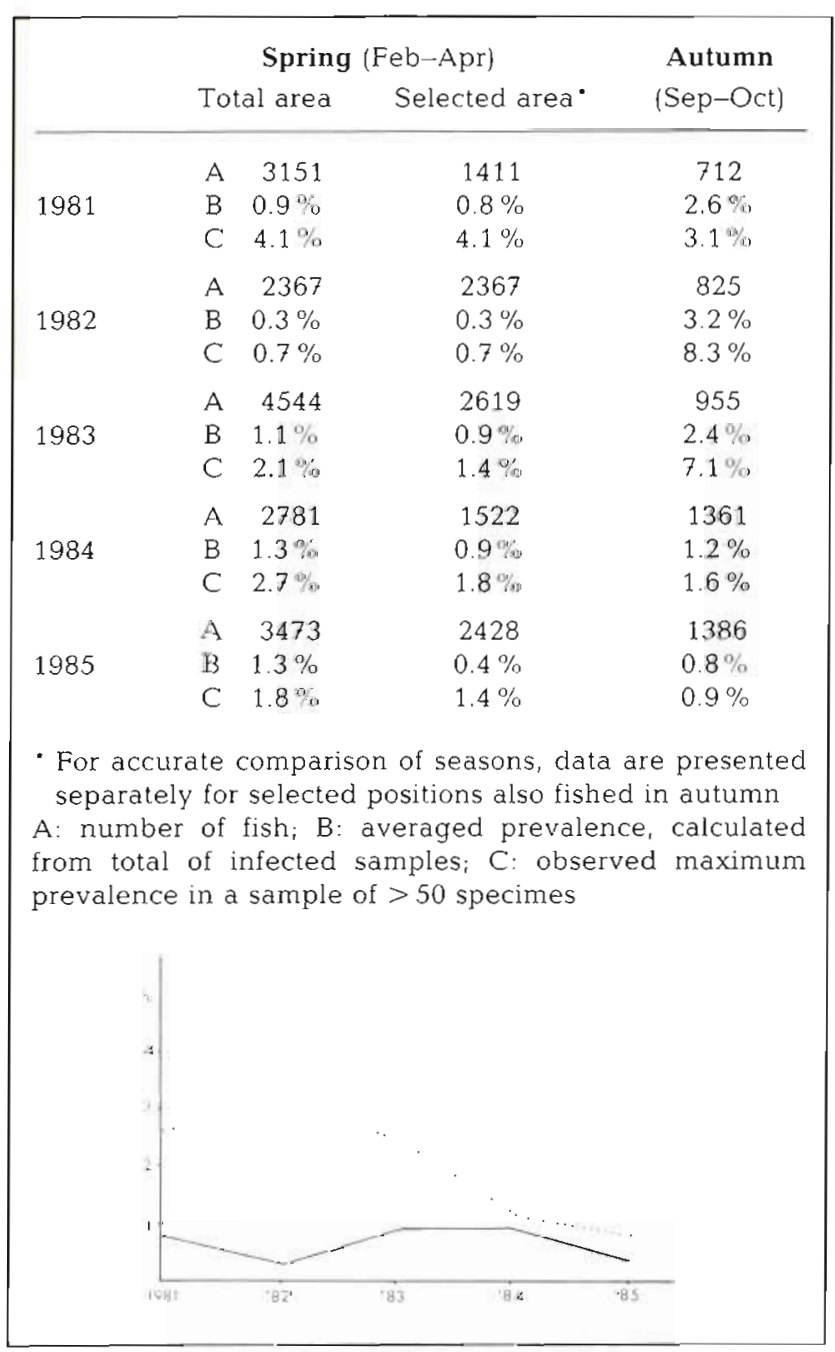

Table 5. Prevalence of Glugea stephani in dab, 1981-1985 Below: Prevalence trend (solid line: spring; dotted line: autumn)

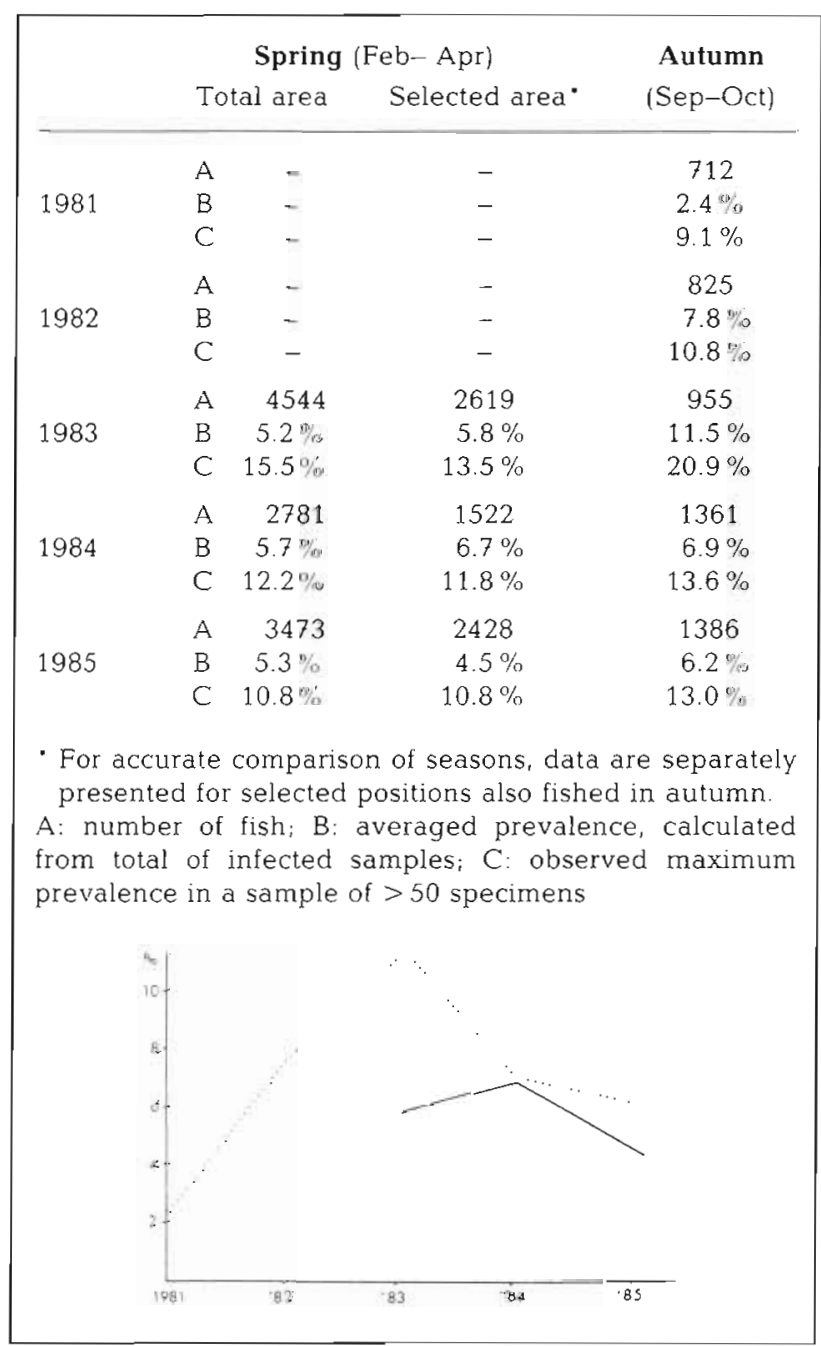


Fig. 5. Presence of $M y x-$ obolus aeglefini in dab, 1981-1985, plotted per area and season. Left: Feb-Apr; right: Sep-Oct
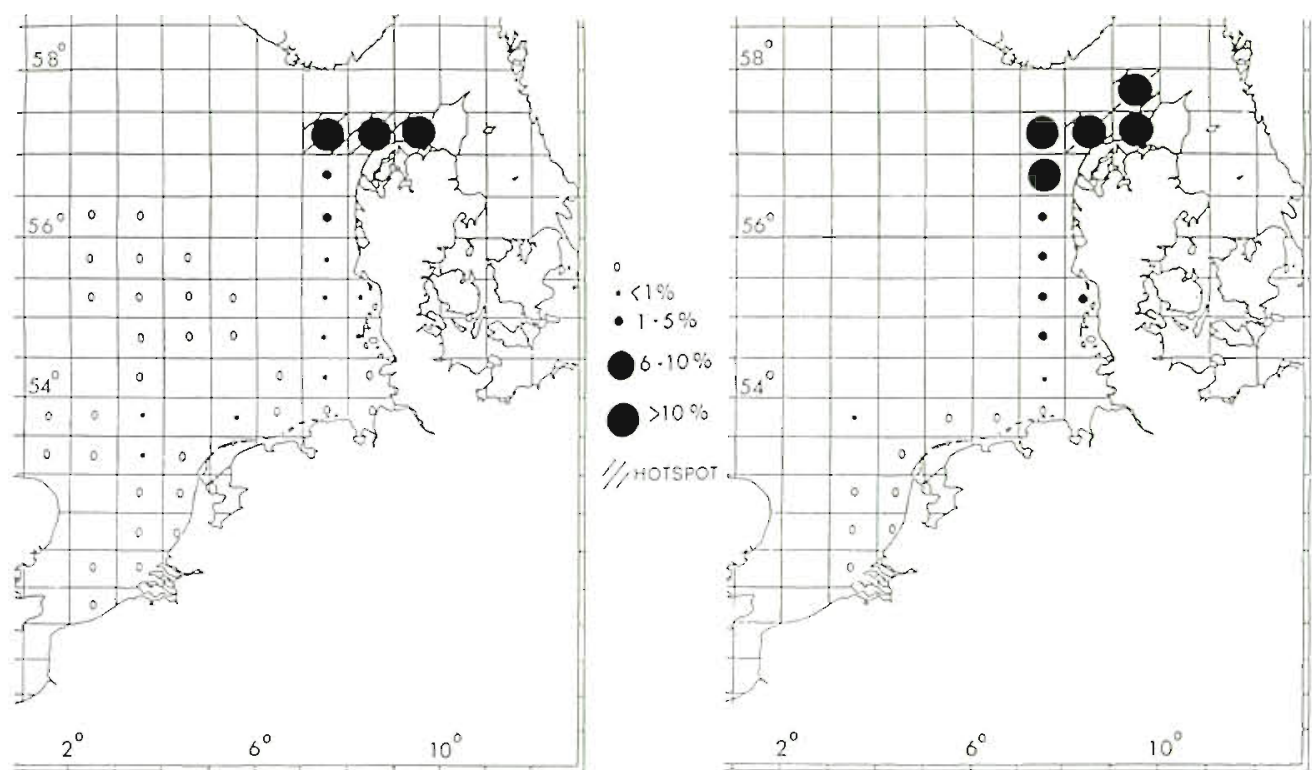

aus (1984) for lymphocystis and epidermal papillomas of dab.

Observations. In order to prevent a strong influence of individual variations, disease recordings were always made by the same people ( 3 persons) with a trained eye. However, rapid handling of fish on board permitted only macroscopic checks, and it must be considered that early disease symptoms could have been overlooked so that observed prevalences may have been lower than their actual level. Observations were always made on the same type of fishery survey, covering the same area, and concentrated on a spring and an autumn sampling when the fish should be in poor or good condition respectively.

Selection and input of data. Sampling was carried out with preferably 100 to 150 specimens of each species with a minimum of 50 specimens per fishing station or per area unit. For area units the grid system of the International Council of the Sea (ICES) was used and all data were plotted in this system, separately per fish species, season and disease. The data of each grid were averaged to provide a general index of prevalence of that area. The area of survey was chosen as large as possible (the coasts of the southeastern part of the North Sea near the coasts of Netherland, Germany and Denmark) in order to cover, as much as possible, different fish populations and different environmental conditions.

Presentation of data. To frame the prevalence into a simple indication system useful for the geographical grid system, the following classification was applied: 0 , $<0.5 \%, 0.5$ to $0.9 \%, 1$ to $1.5 \%,>1.5 \%$; or $0,<1 \%$. 1 to $5 \%, 6$ to $10 \%$ and $>10 \%$, depending on the disease condition. An attempt was also made to delineate areas with consistently high prevalences of disease
Table 6. Prevalences of Myxobolus aeglefini in dab, 1981-1985. Below: Prevalence trend (solid line: spring; dotted line: autumn)

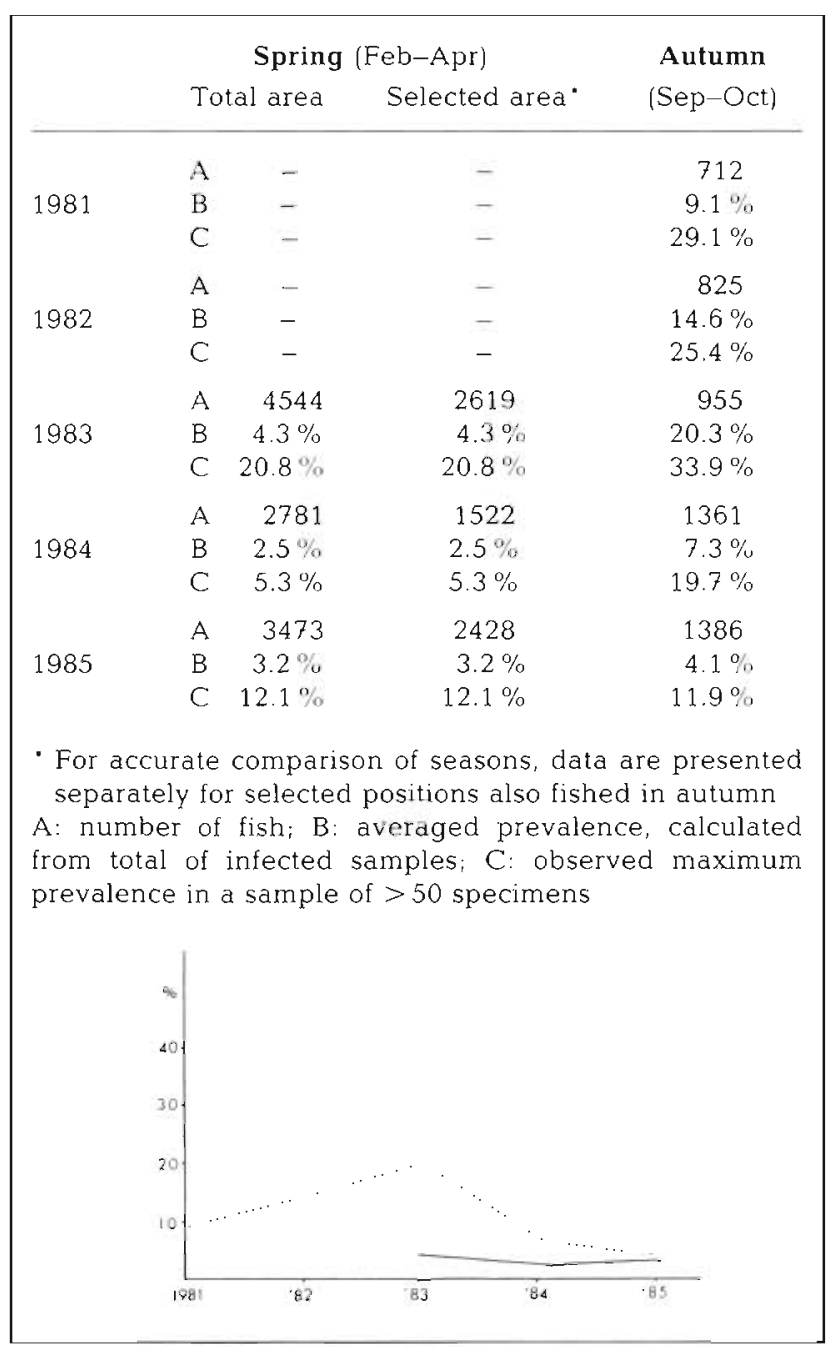




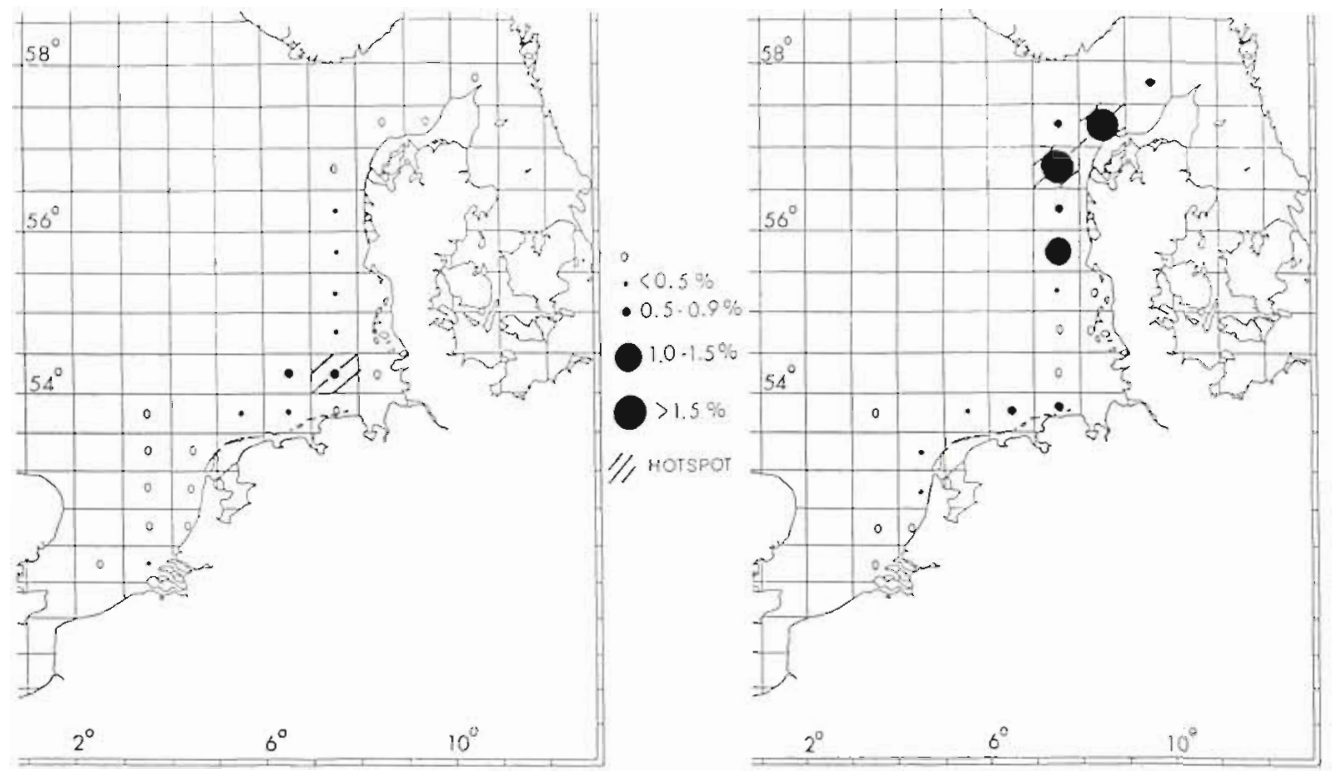

Fig. 6. Presence of lymphocystis in plaice, 1981-1985, plotted per area and season. Left: Feb-Apr; right: Sep-Oct

Table 7. Prevalences of lymphocystis in plaice, 1981-1985. Below: Prevalence trend (solid line: spring; dotted line: autumn)

\begin{tabular}{|c|c|c|c|}
\hline & Spring & (Feb-Apr) & Autumn (Sep-Oct) \\
\hline \multirow{3}{*}{1981} & A & - & 807 \\
\hline & B & _- & $1.0 \%$ \\
\hline & $\mathrm{C}$ & - & $1.9 \%$ \\
\hline \multirow{3}{*}{1982} & A & - & 1175 \\
\hline & B & - & $1.3 \%$ \\
\hline & $\mathrm{C}$ & - & $5.9 \%$ \\
\hline \multirow{3}{*}{1983} & A & 4044 & 1286 \\
\hline & $B$ & $0.5 \%$ & $1.0 \%$ \\
\hline & $\mathrm{C}$ & $1.1 \%$ & $1.9 \%$ \\
\hline \multirow{3}{*}{1984} & A & 1463 & 1640 \\
\hline & $B$ & $1.1 \%$ & $1.7 \%$ \\
\hline & C & $2.8 \%$ & $3.3 \%$ \\
\hline \multirow{3}{*}{1985} & A & 2887 & 1739 \\
\hline & $B$ & $0.6 \%$ & $1.1 \%$ \\
\hline & C & $1.5 \%$ & $2.6 \%$ \\
\hline
\end{tabular}

A: number of fish; $B$ : averaged prevalence, calculated from total of infected samples; $C$ : observed maximum prevalence in a sample of $>50$ specimens

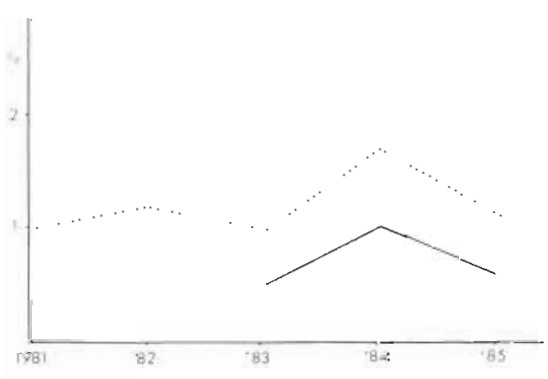

as hot-spot areas. Prevalences $1.5 \times$ above the average prevalence turned out to be suitable for indicating hotspot areas on the grid maps.

\section{RESULTS}

\section{Dab Limanda limanda}

Lymphocystis. This disease showed a seasonal tendency with an increased presence and prevalence in spring (Fig. 1, Table 2). Hot-spot areas were present in the Dogger Bank area and near the northern Danish coast (Fig. 1). Average prevalences were in the range of 0.5 to $4.5 \%$; observed maximal prevalence in one representative fishery sample was $16.1 \%$ (Table 2). Increased tendencies of prevalences were present only in 1983 and 1984 (Table 2)

Hyperplasia/papilloma. In the area searched this disease was found only in dab. A restricted area of infection was observed off the Dutch coast and in the German Bight (Fig. 2). Indications of hot-spots were found near the Dogger Bank and the German Bight (Fig. 2). Clear-cut seasonal effects were observed with the disease being very evident in spring and nearly absent in autumn (Fig. 2). Average prevalences for spring ranged from 0.8 to $2.6 \%$; the observed maximum prevalence in one representative fishery sample was $11.8 \%$ (Table 3 ). From 1982 the prevalence tended to increase (Table 3)

Skin ulcers. This disease tended to be coast-bound, with hot-spots and increasing presence towards the northerm part of the Danish coast (Fig. 3). A seasonal tendency was present with higher prevalences in 
Fig. 7 Presence of ulcers in plaice 1981-1985, plotted per area and season. Left: Feb-Apr; right: Sep-Oct
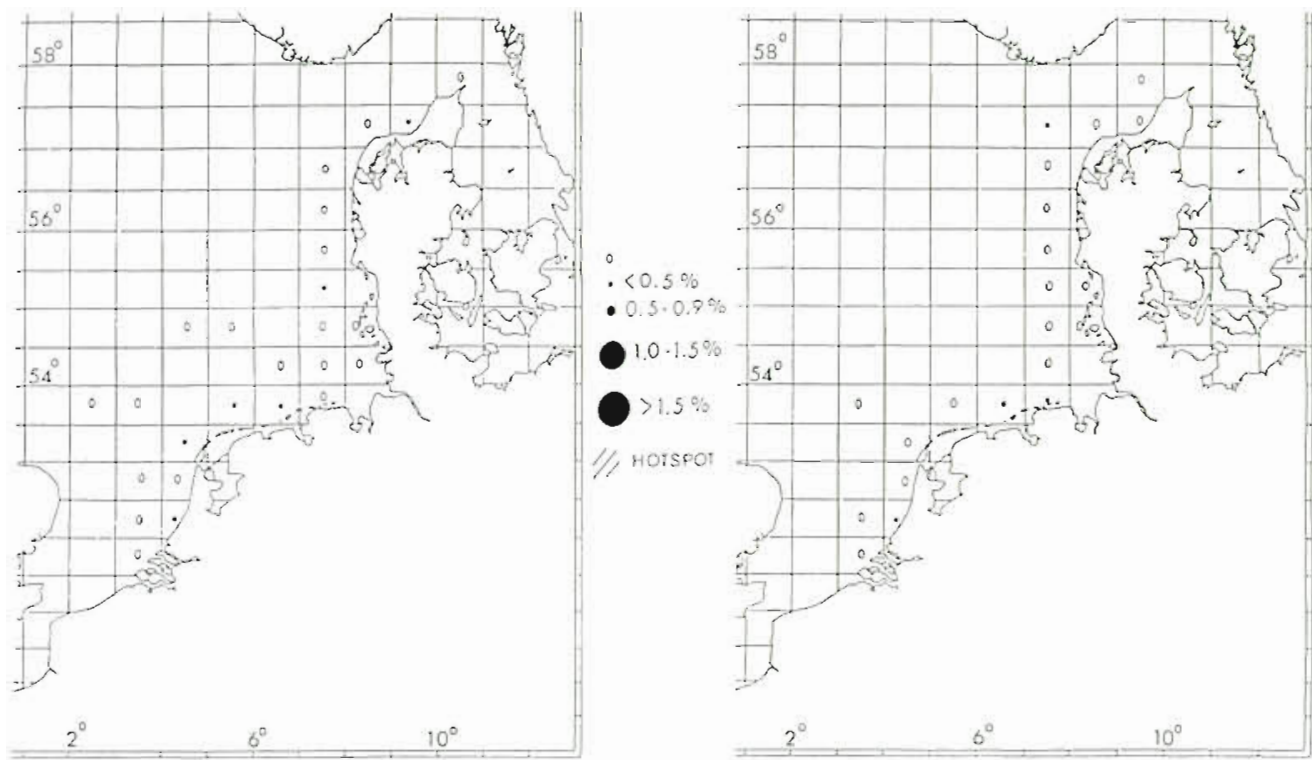

autumn (Table 4). Average prevalences ranged from 0.3 to $3.2 \%$; maximum prevalence in one representative fishery sample was $8.3 \%$ (Table 4). During the recording period a slightly decreasing prevalence trend was observed (Table 4).

Glugea stephani. Occurrence was area-related; the main infection area was located south of $55^{\circ}$ latitude and mainly in the more coastal waters (Fig. 4). Hotspots were situated along the Dutch coast and in the German Bight (Fig. 4). Average prevalences ranged from 2.4 to $11.5 \%$; maximum prevalence in one representative fishery sample reached $20.9 \%$ (Table 5). An increasing trend of infection occurred until 1983; after that year it decreased (Table 5).

Myxobolus aeglefini. A strong area-linked trend occurred in the Danish area north of $56^{\circ}$ latitude (Fig. 5). There was a slight seasonal tendency with increased prevalence in autumn (Table 6). Average prevalences ranged from 2.5 to $20.3 \%$; maximum prevalence in one representative fishery sample was $33.9 \%$ (Table 6). There was an overall tendency for a slight increase in prevalence until 1983; after that year the prevalence decreased (Table 6).

\section{Plaice Pleuronectes platessa}

Lymphocystis. Hot-spot areas of this disease were found in the German Bight and in northern Danish coastal waters (Fig, 6). Some seasonal tendency was present with slightly increased prevalences in autumn contrary to levels in dab which showed increased prevalences in spring). Average prevalences ranged
Table 8. Prevalences of ulcers in plaice, 1981-1985. Below: Prevalence trend (solid line: spring; dotted line: autumn)

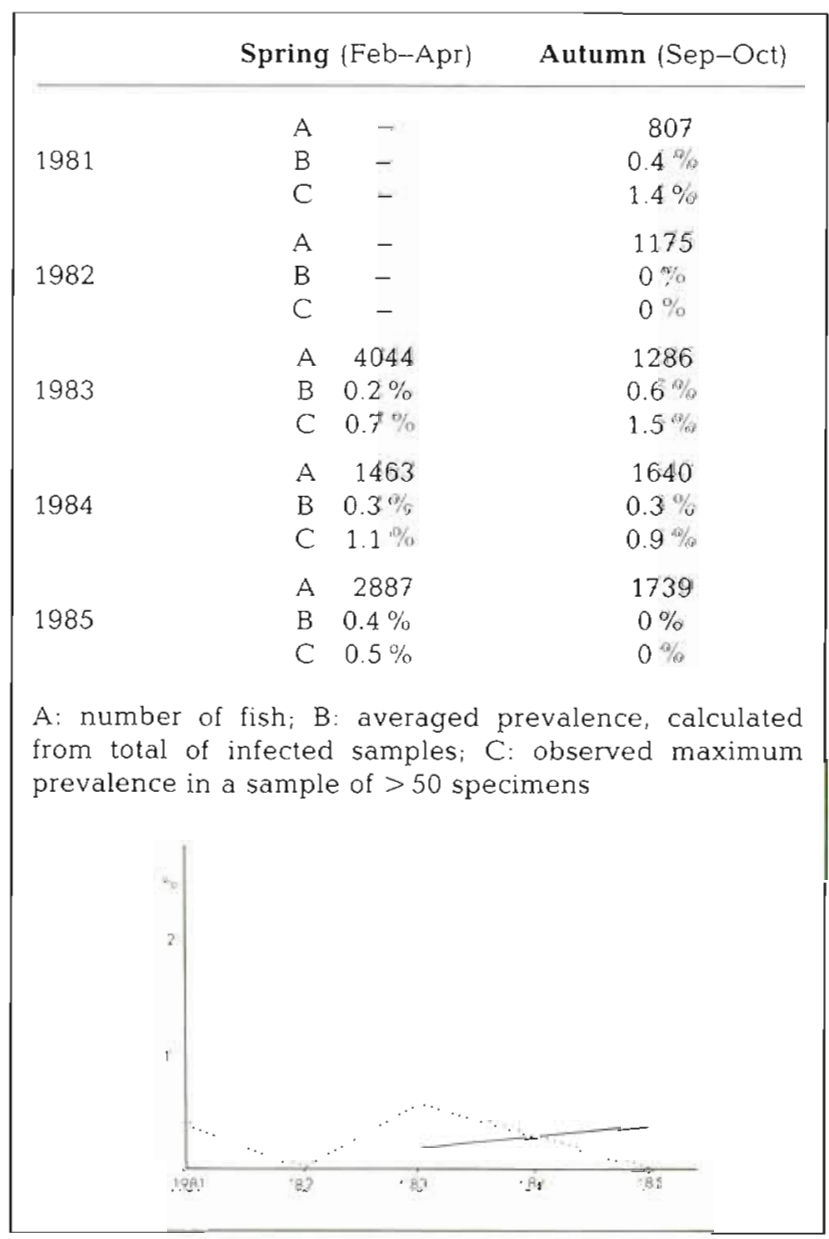




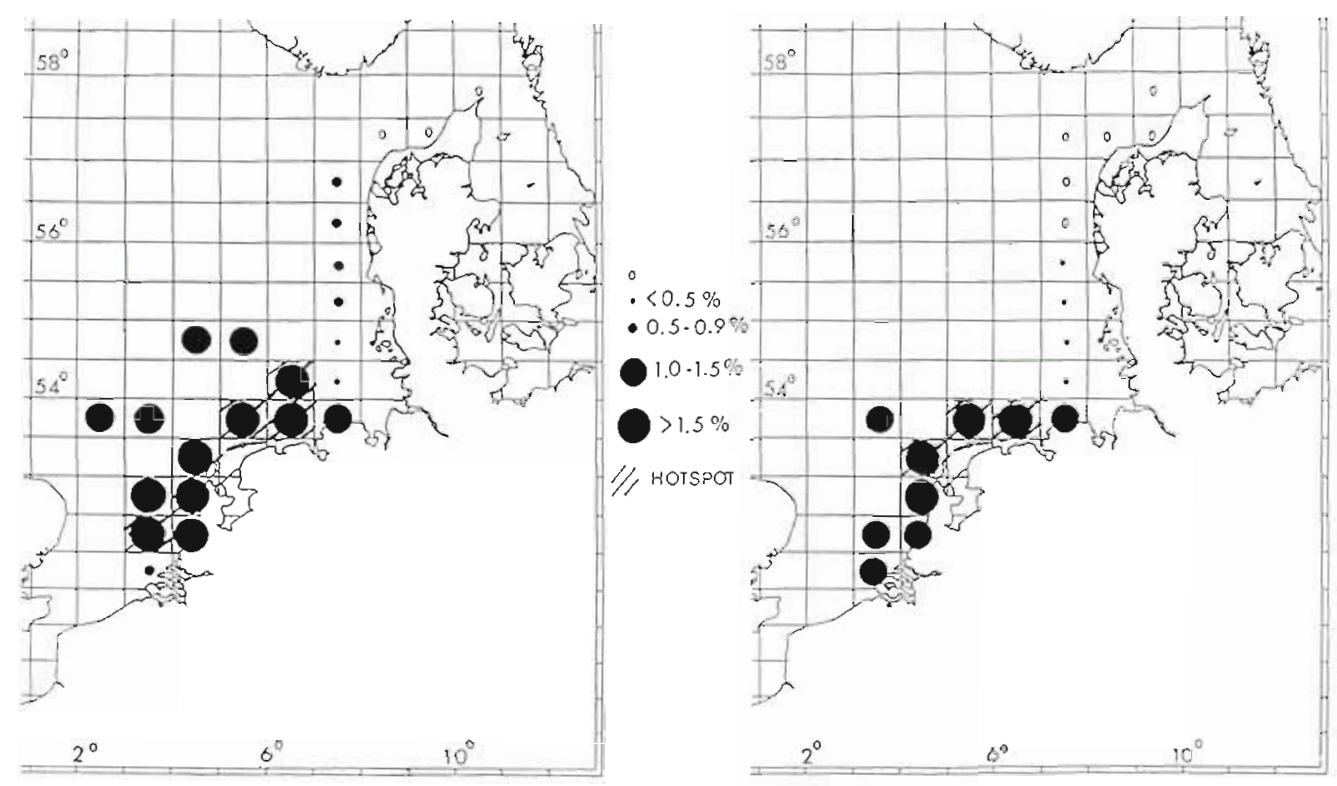

Fig. 8. Presence of Glugea stephani in plaice, 1981-1985, plotted per area and season. Left: Feb-Apr; right: Sep-Oct

Table 9. Prevalences of Glugea stephani in plaice, 1981-1985. Below: Prevalence trend (solid line: spring; dotted line: autumn)

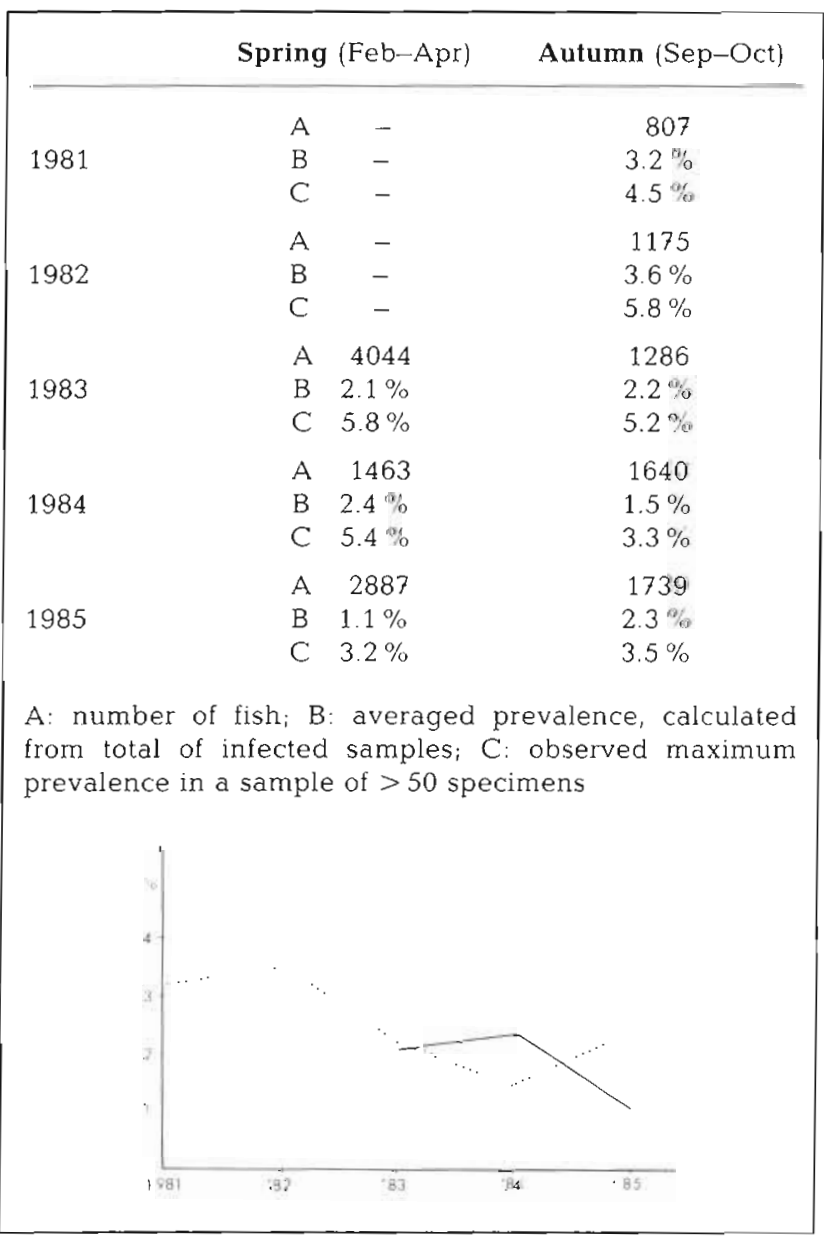

from 0.5 to $1.1 \%$; maximum prevalence in one representative fishery sample was $5.9 \%$ (Table 7 ). No clear-cut trend was found in prevalence changes between 1981 and 1985 (Table 7).

Skin ulcers. A coast-linked tendency occurred (Fig. 7) (as in dab). No clear-cut seasonal or long-term trends of prevalence changes could be established during the recording period. Average prevalences ranged from 0 to $0.6 \%$; maximum prevalence in one representative fishery sample was $1.5 \%$ (Table 8 ).

Glugea stephani. A restricted infection area was situated near the coastal zone and south of $55^{\circ}$ latitude (Fig. 8). Hot-spot areas occurred along the Dutch coast and in the German Bight (Fig. 8). The overall situation is comparable with the findings for dab. Average prevalences ranged from 1.1 to $3.6 \%$; maximum prevalence in one representative fishery sample was $5.8 \%$ (Table 9). A slightly decreasing trend in prevalences was present through the whole period (Table 9).

Myxobolus aeglefini. A restricted infection area was situated along the Danish coast north of $56^{\circ}$ latitude (Fig. 9) (as in dab). Indications for hot-spots were also present. Average prevalences ranged from 18.8 to $58.3 \%$; maximum prevalence in one representative fishery sample was $71.6 \%$ (Table 10). Except for the increased prevalence in 1982 no clear prevalence changes were found for the other years of the recording period.

\section{Cod Gadus morhua}

Presumptive mycobacteriosis. This disease was restricted to the south of $55^{\circ}$ latitude (Fig. 10). Prevalence decreased strongly between 1981 and 1983, and 
Fig. 9. Presence of $M y x-$ obolus aeglefini in plaice, 1981-1985, plotted per area and season. Left: Feb-Apr; right: Sep-Oct
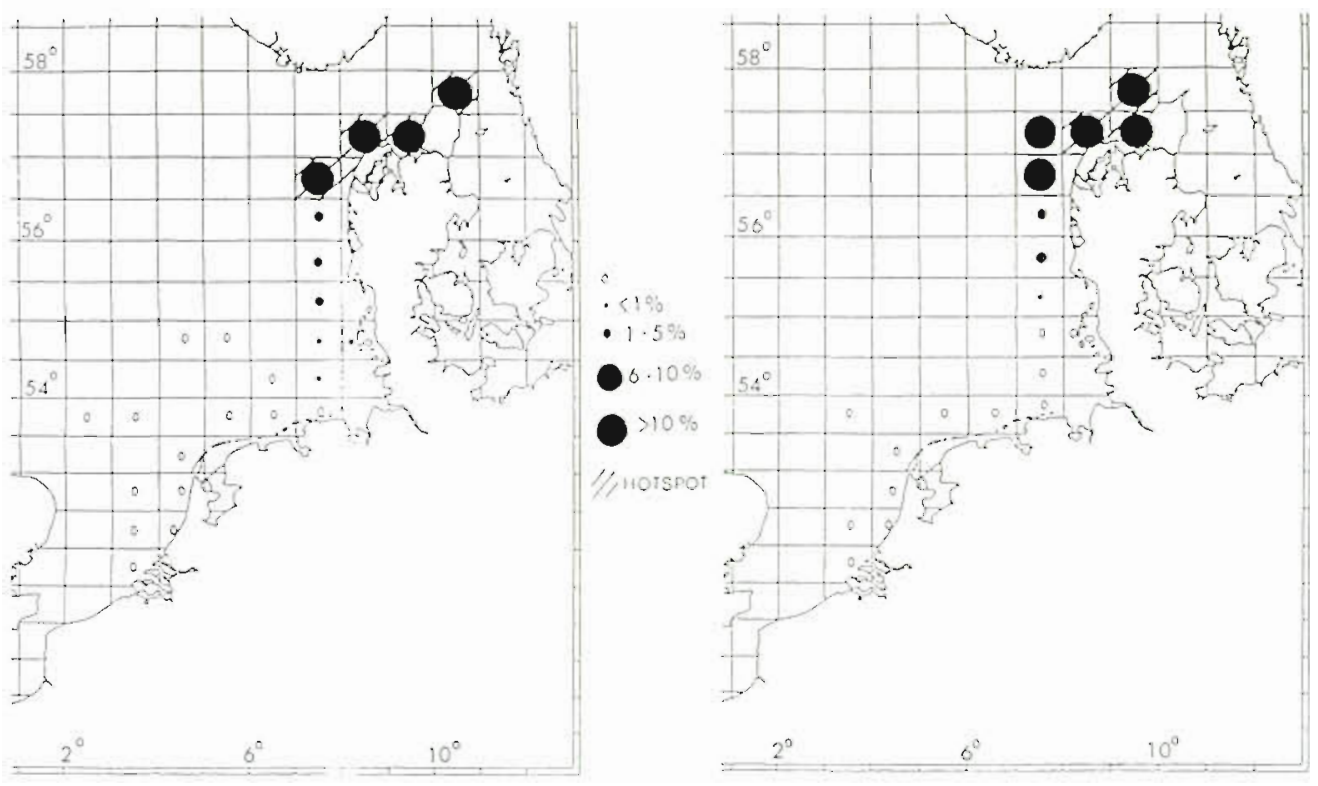

then stabilized (Table 11). From 1981 to 1983 the average prevalence range was 8.9 to $12.5 \%$; it decreased to a range of 1.1 to $3.6 \%$ in the later years. Seasonal changes occurred in the German Bight area, with the disease present primarily in autumn (Fig. 10)

\section{DISCUSSION}

The occurrence of fish diseases in marine wild stocks can vary strongly as a function of fish species, area and season. Differences per fish species are well demonstrated with regard to the epidermal hyperplasia/ papilloma disease which for flatfishes, in the area covered, is strongly associated with dab. For roundfishes, cases of epidermal hyperplasia were described for roughly the same area in gadoid fishes (Watermann \& Dethlefsen 1985). Differences per fish species are also documented for the lymphocystis disease of flatfishes. In the same area, period and season, flounder Plathichthys flesus show much higher sensitivity to this disease (up to $29.3 \%$ prevalence; Vethaak 1985) than dab (up to $5.8 \%$; this study) and plaice (up to $3.3 \%$; this study)

Prevalence differences per area are also demonstrated, e.g. for dab and plaice with Myxobolus aeglefini infection, which is clearly restricted to northern Danish coastal waters. Other infections with arearestricted characteristics are the Glugea stephani infection in dab and plaice, and the presumptive mycobacteriosis of cod; in the area searched both diseases were recorded only south of $55^{\circ}$ latitude. Seasonal differences in prevalences are clearly expressed in the data for lymphocystis, epidermal hyperplasia/papilloma and ulcer disease of dab.
Table 10. Prevalences of Myxobolus aeglefini in plaice, 1981-1985. Below: Prevalence trend (solid line: spring; dotted line: autumn)

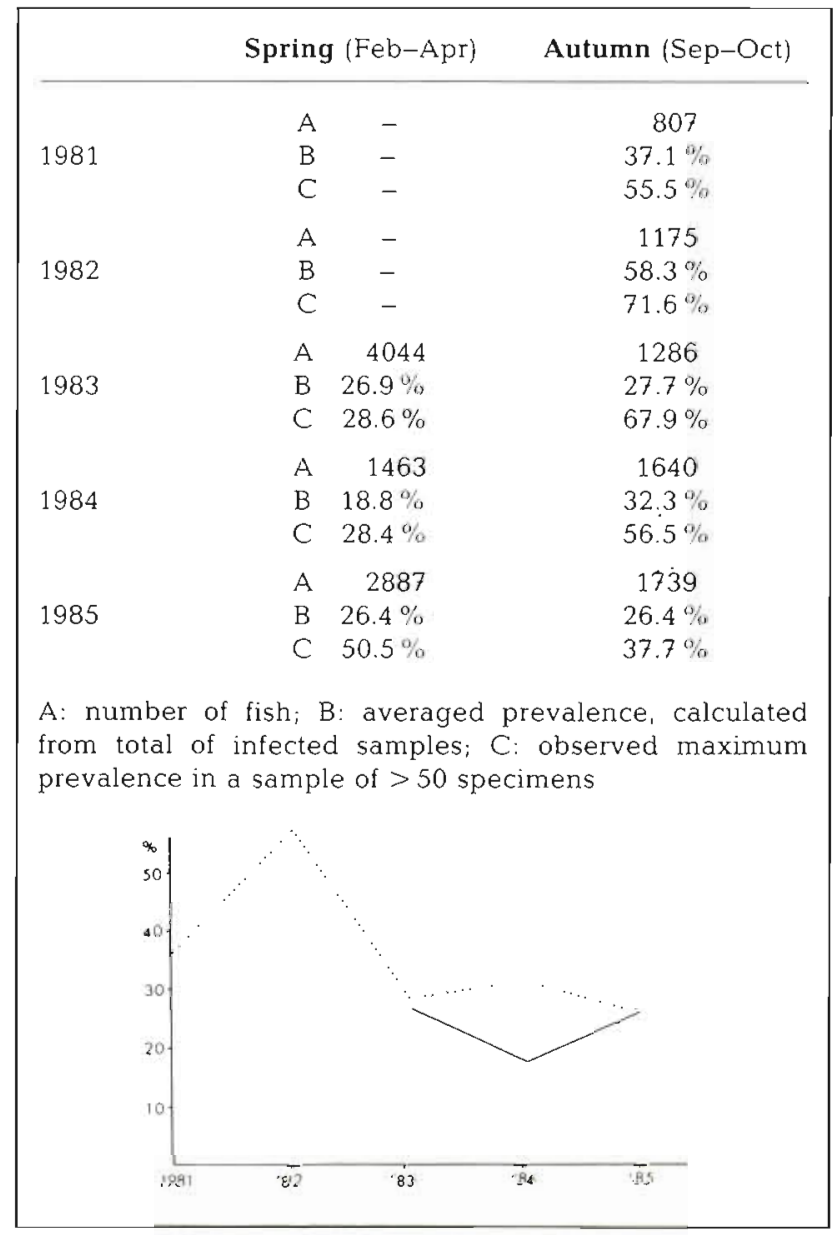



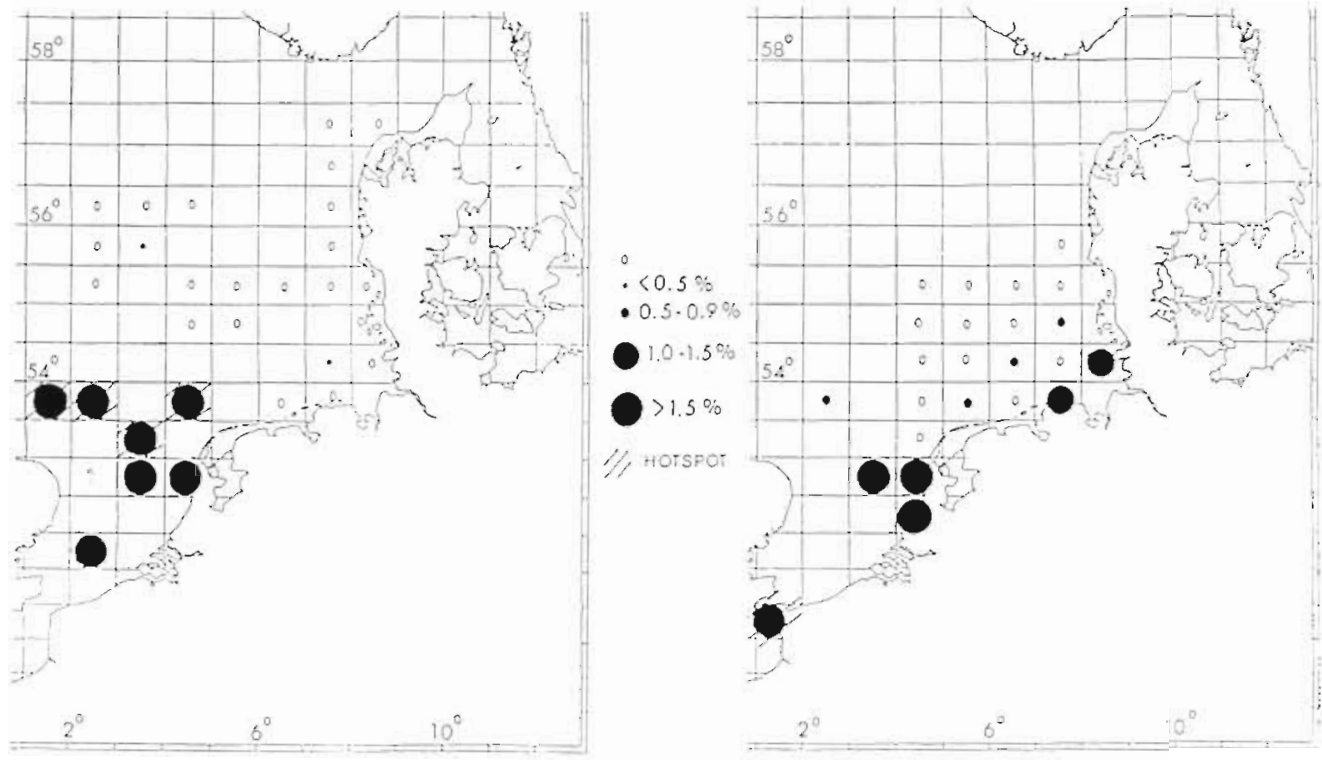

Fig. 10. Presence of presumptive mycobacteriosis in cod, 1981-1985, plotted per area and season. Left: Feb-Apr; right: Sep-Oct
Table 11. Prevalences of presumptive mycobacteriosis in cod, 1981-1985. Below: Prevalence trend (solid line: spring; dotted line: autumn)

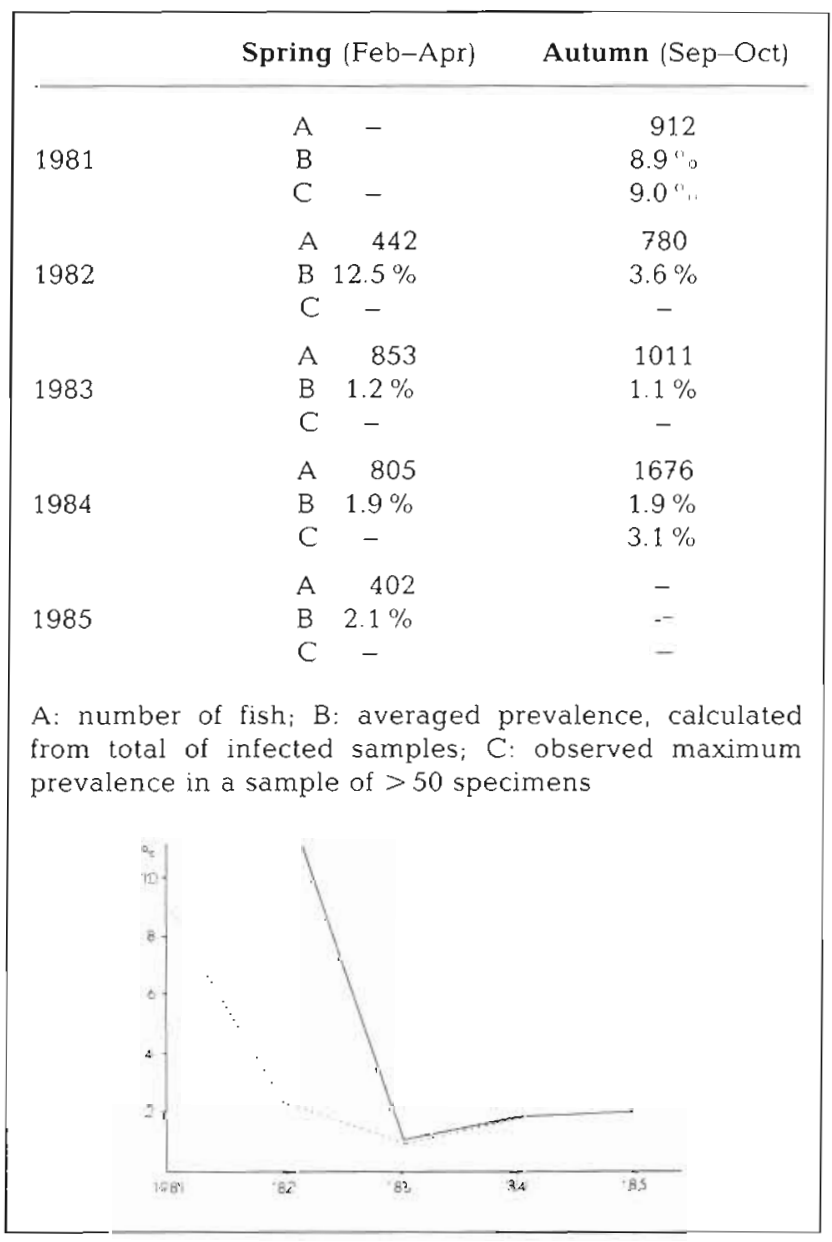

Beside the above-mentioned differences, the fish disease recording programme can also detect trends in changes of prevalences. In the recording period, most of the diseases mentioned reveal changes in prevalences with undulating characteristics, permitting no conclusions in regard to increasing or decreasing trends. Only epidermal hyperplasia/ papilloma of dab and presumptive mycobacteriosis of cod showed, from 1981 to 1985, some trend - increasing and decreasing respectively. For a more definitive evaluation, a longer period of recording is needed. Increase in prevalence of epidermal hyperplasia of dab was also noticed from German long-term recordings (1979 to 1985) in the German Bight (Dethlefsen 1986).

While obtained by simple recording methods, our results on variations in marine fish diseases per fish species, area, season and year, are of comparable value with other short- or long-term studies which were, however, conducted as special fish disease surveys, with or without specific aims to study pollutioncaused relationships (Dethlefsen 1980, 1985, 1986, Möller 1981, Mellergaard \& Nielsen 1984, Wolthaus 1984).

For evaluating data of this standard stock assessment fish disease recording programme, a comparison was made with the total prevalence range composed of studies by Mellergaard \& Nielsen (1984), Wolthaus (1984) and Dethlefsen (1986). A selection was made of the most-sampled area (German Bight or adjacent areas), period (1981-1984), target species (dab), and diseases (epidermal hyperplasia/papilloma and lymphocystis), resulting in the following scheme: 


\begin{tabular}{lccc} 
Disease & Season & $\begin{array}{c}\text { Prevalence } \\
\text { range (com- } \\
\text { posed) }\end{array}$ & $\begin{array}{c}\text { Prevalence } \\
\text { range (recording } \\
\text { programme) }\end{array}$ \\
\hline $\begin{array}{l}\text { Epidermal } \\
\text { hyp/pap }\end{array}$ & $\begin{array}{c}\text { Spring } \\
\text { Autumn }\end{array}$ & $0.4-13.8 \%$ & $0.8-10.3 \%$ \\
Lympho- & Spring & $0.5-17.2 \%$ & $0-2.8 \%$ \\
cystis & Autumn & $0.3-7.3 \%$ & $1.1-16.1 \%$ \\
& & & $0.5-5.8 \%$
\end{tabular}

Based on these data, the present programme largely agrees with special fish disease surveys. There are only slight differences in the minimum and maximum levels of the recording programme. This is probably due to some of the restrictions in standard stock assessment surveys (see 'Materials and Methods').

In conclusion, long-term fish disease recordings carried out with standard stock-assessment surveys are useful and reliable for estimating prevalence levels of certain fish diseases and for detecting abnormal trends in variations as well the existence of hot-spot areas.

\section{LITERATURE CITED}

Bloch, B., Mellergaard, S., Nielsen, E. (1986). Adenovirus-like particles associated with epithelial hyperplasias in dab, Limanda limanda (L.). J. Fish. Dis. 9: 281-285
Dethlefsen, V (1980). Observations on fish diseases in the German Bight and their possible relation to pollution. Rapp. P.-v. Reún. Cons. int. Explor. Mer 179: 110-117

Dethlefsen, V (1985). Review on the effects of dumping of wastes from titanium dioxide production in the German Bight. Coun. Meet. int. Coun. Explor Sea C.M.-ICES 1985/E: 2

Dethlefsen, V (1986). Langzeitveränderungen der Krankheitshäufigkeiten der Kliesche (Limanda limanda) in der Deutschen Bucht und der Doggerbank. Infn. Fischw. $33(1): 16-21$

Johnstone, J. (1906). Internal parasites and diseased conditions of fishes. Lancashire Rep. 15: 170-208

Mellergaard, S., Nielsen, E. (1984). Preliminary investigations on the eastern North Sea and the Skagerrak dab (Limanda limanda) populations and their diseases. Coun. Meet. int. Coun. Explor. Sea C.M.-ICES 1984/E: 28

Möller, H. (1981). Fish diseases in German and Danish coastal waters in summer 1980. Kieler Meeresforsch. (Sonderh.) 29: 1-16

Vethaak, A. D. (1985). Prevalence of fish diseases with reference to pollution of Dutch coastal waters. Netherlands Institute for Fishery Investigations, IJmuiden, Report CA 85-01 E

Watermann, B., Dethlefsen, V (1985). Epidermal hyperplasia and dermal degenerative changes as cell damage effects in gadoid skin. Arch. FischWiss. 35 (3): 205-221

Wolthaus, B.-G. (1984). Seasonal changes in frequency of diseases in dab, Limanda limanda, from the southern North Sea. Helgoländer Meeresunters. 37 375-387 